\title{
Observações sobre o Projeto FLORAM
}

\section{BENEDITO VASCONCELOS MENDES*}

or ser de abrangência mundial, necessitando, portanto,
de extensas áreas de muitos países para reflorestar, o
Projeto FLORAM não deve excluir as regióes secas

(áridas e semi-áridas), em virtude, principalmente, da grande expressão geográfica destas terras. Um terço da superfície terrestre é de terras secas. Metade dos países do mundo possui parte ou a totalidade de seus territórios constituídos por terras áridas ou semi-áridas. Somente os trópicos semi-áridos do planeta abrangem uma área de, aproximadamente, 20 milhóes de $\mathrm{km}^{2}$, espalhados em meia centena de países de todos os continentes e representam mais da metade das terras agricultáveis do mundo.

\section{O Projeto FLORAM deve conter um plano de desenvolvimento sócio-económico para o semi-árido nordestino baseado em atividades agrossilvopastoris.}

Considerando que, em termos globais, o Projeto FLORAM coloca o interesse ecológico acima do econômico, nada mais lógico do que, também, no âmbito nacional, se procure agregar ao objetivo principal outras vantagens ambientais e sociais, para que se consiga, a partir do interesse sócio-ecológico regional, alcançar o objetivo universal. Neste particular, a regiáo semi-árida do Nordeste brasileiro, por ser muito vasta, pobre e populosa e por possuir ecossistemas frágeis, altamente vulneráveis à degradaçáo, deve ser priorizada em qualquer plano nacional de reflorestamento que prefirá as vantagens ecológicas e/ou sociais ao interesse puramente industrial. * Benedito Vasconcelos Mendes é professor tinular da Escola Superior de Agricultura de
Mossoró-ESAM. 
Sugerimos que o reflorestamento desta regiăo seja voltado, prioritariamente, para o desenvolvimento rural e para o controle da desertificação, dando mais prioridade aos aspectos sociais e ecológicos do que mesmo ao econômico.

As deficiências de clima e solo regionais limitam a produtividade madeireira para fins de produção de celúlose, porém, não impedem o reflorestamento com essências perenifólias xerófilas de fins múltiplos como certas frutíferas, forrageiras e produtoras de matérias-primas industriais como óleo, cera, borracha, resinas, tanino, cosméticos, produtos farmacêuticos, fibras e outros. A alegaçáo de que o semi-árido nordestino não deve ser reflorestado por não possibilitar altas produtividades de fitomassa náo deve ser aceita, mormente em . um projeto predominantemente ecológico como se propóe a ser o Projeto FLORAM. Ao contrário, a região semi-árida nordestina, por possuir vocação natural para a desertificação, deve merecer um tratamento privilegiado em relaçăo às outras áreas menos degradadas do país. Sabe-se que a ocorrência de secas periódicas, as características climáticas e edáficas e a pressão humana, traduzida, principalmente, pelo indiscriminado desmatamento e superpastejo dos animais domésticos que o Polígono das Secas, apresenta sáo os principais responsáveis pelo acelerado processo de desertificação que a regiáo está sofrendo.

Para a recuperação das áreas degradadas do Nordeste seco, sugerimos que o Projeto FLORAM seja enriquecido com um plano de açăo agroflorestal para promover o desenvolvimento sócio-econômico regional. Assim, além de contribuir para, em termos locais, atingir o objetivo principal, agregam-se ao projeto outros benefícios ecológicos, sociais e econômicos para esta regiáo e, conseqüentemente, para o país.

\section{No semi-árido nordestino existem plantas perenifólias xerófilas que possuem elevada capacidade de fixação de $\mathrm{CO}_{2}$ e que produzem frutos produtos de grande valor económico.}

Com relaçăo à eficiência na fixação de $\mathrm{CO}_{2}$ e ao retorno econômico. dos investimentos que serão feitos, o reflorestamento com árvores frutíferas, forrageiras e industriais (produtoras de óleo, cera, resinas etc.) perenifólias xerófilas, atende a estes dois requisitos, haja vista a grande produção de frutos de elevado valor comercial, de produtos industriais e de massa verde que apresentam algumas das espécies recomendadas para estes fins. 


\section{A regiáo seca nordestina possui extensas áreas disponíveis para atividades agrossilvopastoris.}

A região semi-árida nordestina oferece grande disponibilidade de terras que, no momento, estáo ociosas e que se prestam para programas de reflorestamento. Sáo terras desmatadas, de baixo valor venal, que não estão sendo utilizadas na agricultura. Programas agrossilvopastoris poderão transformar estas áreas ociosas em terras altamente produtivas, onde a ecologia poderá ser compatibilizada com o desenvolvimento social e econômico da região.

\section{O Projeto FLORAM deve propiciar maior porcentagem de reflorestamentos com fins múltiplos, mediante $o$ acréscimo de 5 milhóes de hectares a serem reflorestados no semi-árido nordestino.}

Para a recuperação das treas degradadas do Nordeste seco, sugerimos que 0 Projeto FLORAM seja enriquecido com um plano de ação agroflorestal para promover o desenvolvimento sócio-económico regional.
Considerando as péssimas condiçóes de preservação ambiental verificadas em quase todo território brasileiro, a porcentagem de $71,8 \%$ de reflorestamento industrial propriamente dito, que é proposto no referido Projeto, é muito elevada. Para diminuir esta taxa, recomendamos o aumento da porcentagem de reflorestamentos com finalidade múltipla, mediante o acréscimo de 5 milhổes de hectares com este tipo de reflorestamento no Nordeste seco. Assim, a inclusáo da regiāo semi-árida do Nordeste pára ser reflorestada em larga escala, obedecendo a uma estratégia fundamentada $\mathrm{em}$ açóes

agrossilvopastoris, servirá para aumentar a participaçáo dos plantios ecológicos/utilitários em relação àqueles destinados à produção de celulose. $O$ reflorestamento de 5 milhōes de hectares com essências xerófilas, obedecendo a um plano que possibilite a participaçáo do maior número possível de pequenas e médias propriedades rurais, localizadas na vasta regiảo semi-árida dos nove Estados nordestinos, contribuirá de maneira efetiva para capacitar o Polígono das Secas para melhor conviver com as secas periódicas.

\section{A utilização da região seca do Nordeste para reflorestamento deve levar em consideraçắo os critérios estratégicos do tema conservação e uso do solo estabelecido no Projeto FLORAM.}

As estratégias e planos de açáo estabelecidos para o temá "Reflorestamento e Uso do Solo" do Projeto FLORAM se encaixam muito bem nos critériös que devem ser obedecidos no Plano para o Desenvolvimento Sócio-Econômico desta região, que deve ser baseado $\mathrm{em}$ atividades agrossilvopastoris. Sugerimos, entretanto, 
algumas alteraçóes nas estratégias e planos de ação, como mostra o quadro a seguir:

\begin{tabular}{|c|c|}
\hline \multicolumn{2}{|l|}{ REFLORESTAMENTOO E USO DE SOLO } \\
\hline ESTRATEGIAS & PLANOS DE AÇÃO \\
\hline $\begin{array}{l}\text { Integrar a atividade florestal em Greas pre-selecionadas, com a - } \\
\text { produçao agropecúbria regional, melhorando a produtividade }\end{array}$ & $\begin{array}{l}\text { Incentivar o desenvolvimen- } \\
\text { to agrosilvipastoril }\end{array}$ \\
\hline $\begin{array}{l}\text { Reflorestar áreas de solos degradados visanda a produçáo } \\
\text { agropecubria e recuperaçáo de solos }\end{array}$ & $\begin{array}{l}\text { Propiciar o gerenciamento } \\
\text { integrado dos recursos hi- } \\
\text { dricos }\end{array}$ \\
\hline $\begin{array}{l}\text { Incluir o reflorestamento na organizaçðo dos espaços rurais } \\
\text { visando a diversificação das atividades económicas }\end{array}$ & $\begin{array}{l}\text { Intensificar o reflorestamen- } \\
\text { to em areas de formaçóes } \\
\text { abertas, regióes degrada- } \\
\text { das e areas de solos erodi- } \\
\text { dos }\end{array}$ \\
\hline $\begin{array}{l}\text { Aumentak a contribuiçoo florestal para a conservaçáo do meio } \\
\text { ambiente e eventual controle da desertificaçáo e/ou erosøo dos } \\
\text { solos }\end{array}$ & $\begin{array}{l}\text { Avaliar taxas de ocupação } \\
\text { nas d́reas passiveis de reflo- } \\
\text { restamento, compatibilizan- } \\
\text { do preservaçăo de ecossis- } \\
\text { ternas naturais agroecos- } \\
\text { sistemas }\end{array}$ \\
\hline
\end{tabular}

\section{O Polígono das Secas necessita gerar tecnologias para passar a produzir matérias-primas industriais nobres, de origem vegetal.}

A regiáo seca do Nordeste apresenta grande potencialidade para a exploraçáo econômica de árvores xerófilas fornecedoras de matérias-primas industriais, como as produtoras de óleo, cera, borracha, tanino, resinas, cosméticos, produtos farmacêuticos, fibras e outros produtos. Para viabilizar o reflorestamento da regiáo com estas plantas, sugerimos algumas modificaçóes nas "Estratégias para o Reflorestamento nos Sertōes do Nordeste Seco" que estão incluídas no item "Estratégias Diferenciadas por Domínios e Espaços Regionais" , conforme o quadro que segue:

\begin{tabular}{|c|c|}
\hline \multicolumn{2}{|c|}{ ESTRATÉGIAS PARA O REFLORESTAMENTO NOS SERTŐES DO NORDESTE SECO } \\
\hline ESTRATEGIAS & ESPAÇOS \\
\hline $\begin{array}{l}\text { Esforço intensivo e permanente visando a geraçao de tecnolo- } \\
\text { gias para viabilizar a utilizaç6o de árvores xerbfilas de importan- } \\
\text { cia industrial, como as produtoras de bleo, cera, borracha, re- } \\
\text { sinas e outros produtos }\end{array}$ & $\begin{array}{l}\text { XXV Sertoes do Nordeste: } \\
\text { Núcleos de refloresta- } \\
\text { mento com essências } \\
\text { adaptáveis e refloresta- } \\
\text { mentos ecológicos de } \\
\text { Beiro Rio. }\end{array}$ \\
\hline
\end{tabular}
regiăo, com leguminosas arboreas xerbfilas forrageiras e/ou com frutiferas xerbfilas

Promover o reflorestamento das margens dos rios e riachos intermitentes com essências nativas

Possibilitor o aumento da Ǵrea plantada com cajueiro nos litorais secos dos Estados do Rio Gronde do Norte e Ceará e nas regióses do agreste, de tabuleiro baixos platós

Possibilitar o reflorestamento com umbuzeiro das caatingas elevadas, como as regibes do Cariri paraibano, serras do Serid́́ norte-riograndense, agreste piauiense e caatingas pernambucanos $\theta$ baianas 